\title{
Spatial relationships of heavy rains in the Czech Republic
}

\author{
S. Bek ${ }^{1}$, J. Ježek ${ }^{1}$, and V. Bližňák ${ }^{2,3}$ \\ ${ }^{1}$ Institute of Applied Mathematics and Information Technologies, Charles University in Prague, Faculty of Science, \\ Czech Republic \\ ${ }^{2}$ Institute of Atmospheric Physics, ASCR, Czech Republic \\ ${ }^{3}$ Department of Physical geography and geoecology, Charles University in Prague, Faculty of Science, Czech Republic
}

Received: 30 December 2009 - Revised: 5 March 2010 - Accepted: 5 March 2010 - Published: 26 March 2010

\begin{abstract}
Study of heavy rain events and their spatial distribution are of great importance. Such events cause local flooding, accelerate soil erosion and cause damage on property. Data for this study were derived by Sokol and Bližňák (2009) from radar reflectivity and daily rain gauge measurements for the period of 2002-2008. We selected heavy rain events using spatial and intensity constrains. We studied relationships between heavy rains, altitude and terrain roughness. Heavy rain totals correlate with both altitude and terrain roughness globally over the Czech Republic. The correlation is also significant for extreme heavy rain totals. The correlation of heavy rain intensities with altitude was not proven. The highest rates of average intensities are located in the south-eastern parts of the Czech Republic. The spatial distribution of heavy rain frequencies strongly corresponds to the spatial distribution of heavy rain totals. The highest percentage of heavy rains in total precipitation is located in the north-west of the Czech Republic. The extreme heavy rains occupy higher altitudes.
\end{abstract}

\section{Introduction}

Heavy rains during the warm period of the year (April to September) are usually caused by strong convection of air mass. Such rain events cause local flash floods, accelerate soil erosion and cause damage on property. In addition, they are hard to be predicted and the knowledge about their spatial distribution (over the Czech Republic) is insufficient. It is well-known that the spatial properties of precipitation correspond to orography. The relations were studied from various aspects. For example, Basist et al. (1994) studied relationships between annual precipitation and six topographic

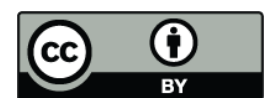

Correspondence to: S. Bek

(bek@natur.cuni.cz) variables, Sevruk and Mieglitz (2002) studied the relationship between daily precipitation and altitude, Allamano et al. (2009) annual maximum sub-daily precipitation, duration and altitude, Haiden and Pistornik (2009) the ones between 12-h precipitation and altitude. Daikaru et al. (2004) studied rainfall amount, intensity, duration and frequency relationships with altitude.

Sokol and Bližňák (2009) studied correlation relationships between precipitation totals of short-term heavy rainfalls and altitude. They focussed on heavy rain data (related to convective storms) and studied the impact of altitude on the precipitation totals. They concluded that the global correlation of the totals decreases with the increasing threshold. For heavy rains, they did not find dependence of the precipitation totals on altitude.

Our paper extends the effort of Sokol and Bližňák (2009) and presents new results regarding the correlation of heavy rains with orography under differently defined heavy rain events.

\section{Basic data}

We use the same basic data as Sokol and Bližňák (2009) - the precipitation data derived from radar reflectivity and daily rain gauge measurements by merging procedure published by Sokol (2003). It consists of $1 \mathrm{~h}$ - precipitation totals for the warm period of the year (April to September) of the years 2002-2008 in the horizontal resolution of $1 \mathrm{~km} \times 1 \mathrm{~km}$ covering the Czech Republic (approx. 78000 pixels). Only precipitation intensities higher than $1 \mathrm{~mm} / \mathrm{h}$ were considered. The data were complemented by altitude information. Hourly precipitation totals were calculated by time integration based on radar reflectivity measurements performed every $10 \mathrm{~min}$ (starting hh:00 UTC and ending hh:50 UTC). Each data element is described by: $\mathrm{x}$ and $\mathrm{y}$-coordinate, date, hour, precipitation amount and altitude.

Published by Copernicus Publications on behalf of the European Geosciences Union. 

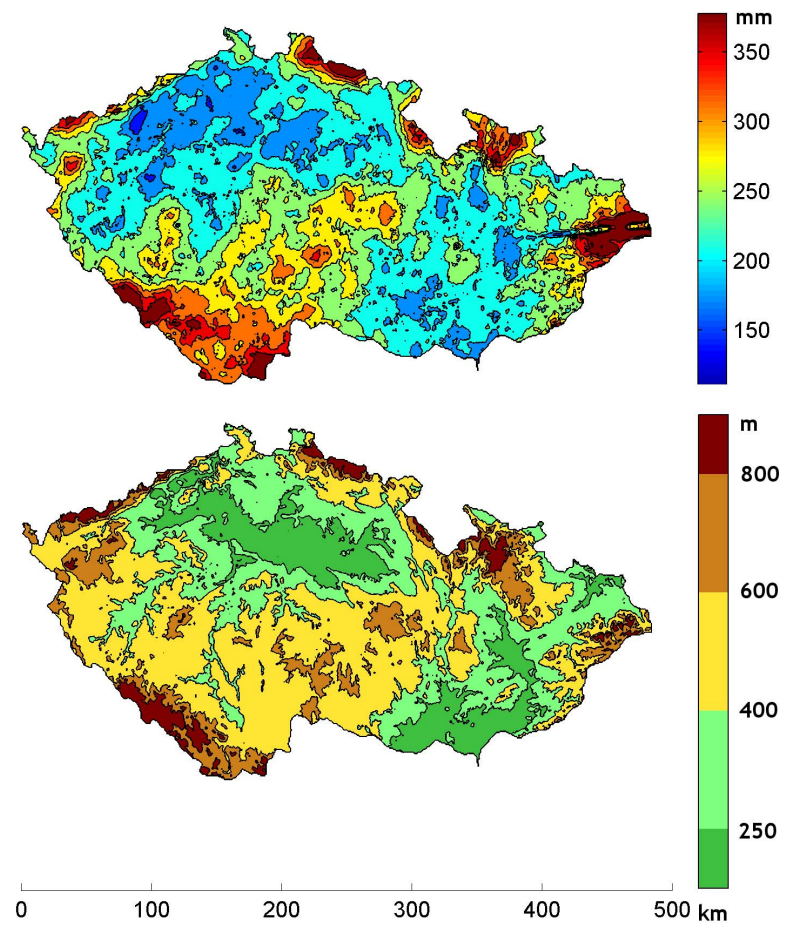

Fig. 1. Average annual precipitation amount for warm period of the years 2002-2008 (up) and altitude of the Czech Republic (down).

From the altitude dataset we created a simple characteristic of terrain roughness. We used a $3 \times 3$ pixel moving window (9 sq. km) and computed standard deviation of the 9 pixel values. The standard deviation represented the terrain roughness in the central pixel.

\section{Heavy rains selection}

In order to select relevant data regarding the heavy rains the basic data have to be processed. Sokol and Bližňák (2009) integrated the data in time, created precipitation events consisting of one pixel location and consecutive precipitation information (e.g., event of $1 \mathrm{sq}$. $\mathrm{km}$ and of $3 \mathrm{~h}$ duration) and selected heavy rain events by a threshold intensity.

We processed the data another way. For every hour, we created a raster representing the actual precipitation situation over the Czech Republic. Then we identified clusters composed of non-null pixels. These clusters represent rain events (each of an 1-h duration) from which we selected the heavy rain events as the ones fulfilling the following conditions: i) average precipitation of the cluster is higher than a chosen threshold $T_{\text {prec }}$ (typically $T_{\text {prec }}=5$ or more $\mathrm{mm}$, ii) $\max$ imum precipitation within the cluster is higher than $15 \mathrm{~mm}$. By these conditions we aimed to guarantee that the event is strong and has a core as it is common for convective precipitation (e.g. Steiner et al., 1995; Biggerstaff and Listemaa, 2000). The second condition also helps to filter badly clus-

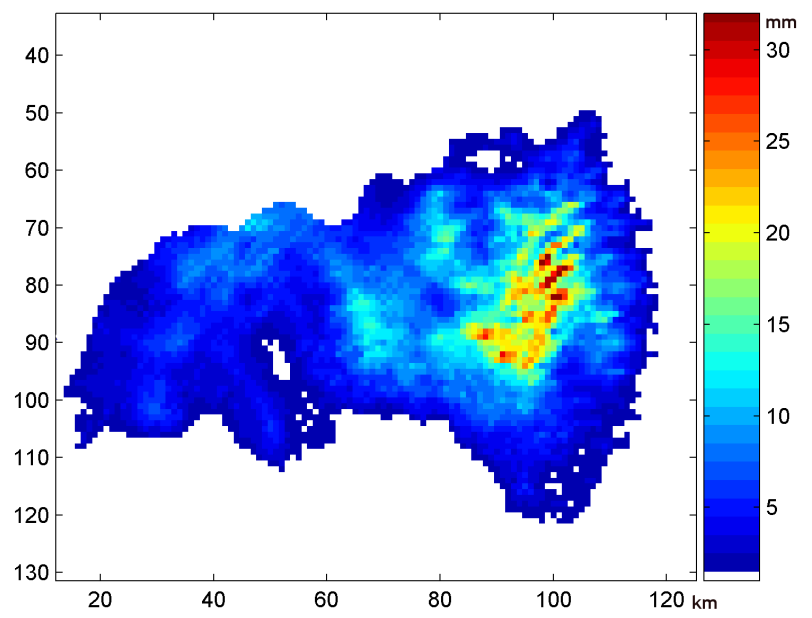

Fig. 2. Sample cluster created from basic data set and representing one heavy rain event.

tered patterns and very small clusters. An example of a cluster (event) is shown in Fig. 2.

All the events selected using the threshold $T_{\text {prec }}=5 \mathrm{~mm}$ were spatially overlaid. The summed rain amounts, divided by 7 (years) to obtain the annual average, define the dataset called heavy rain totals. Note that the map of the ratio of the heavy rain totals to the total precipitation shows remarkably high ratios in the north-west parts which is, in total, a very dry area in the rain shadow of the mountains on the western border of the Czech Republic. (see Fig. 3).

\section{Heavy rain - orography relationship}

\subsection{Heavy rain totals}

In their study Sokol and Bližňák (2009) did not find significant correlation between altitude and heavy rains for high intesity thresholds. The correlation decreased with increasing threshold.

We were therefore interested in whether we find similar results with differently defined heavy rain events. First, we examined the correlation of the heavy rain totals $\left(T_{\text {prec }}=5 \mathrm{~mm}\right)$ and altitude. We found global correlation over the Czech Republic, $r=0.43$. Due to the spatial autocorrelation of the datasets, an assessement of the significance of the correlation cannot be done using a standard correlation test. In order to find out the critical value of the correlation coefficient corresponding to our problem, we used the bootstrapping method of phase scrambling (Davis and Hinkley, 1997). The method is based on repeated simulation of datasets which have similar spatial structure (covariance) as the elevation and heavy rain totals. By this method, we obtained the critical value of correlation $r_{k}=0.2$ (significance level $\alpha=0.05$ ) and concluded that the correlation between heavy rain totals and altitude $\left(r=0.43>r_{k}\right)$ was proven. We used the same 

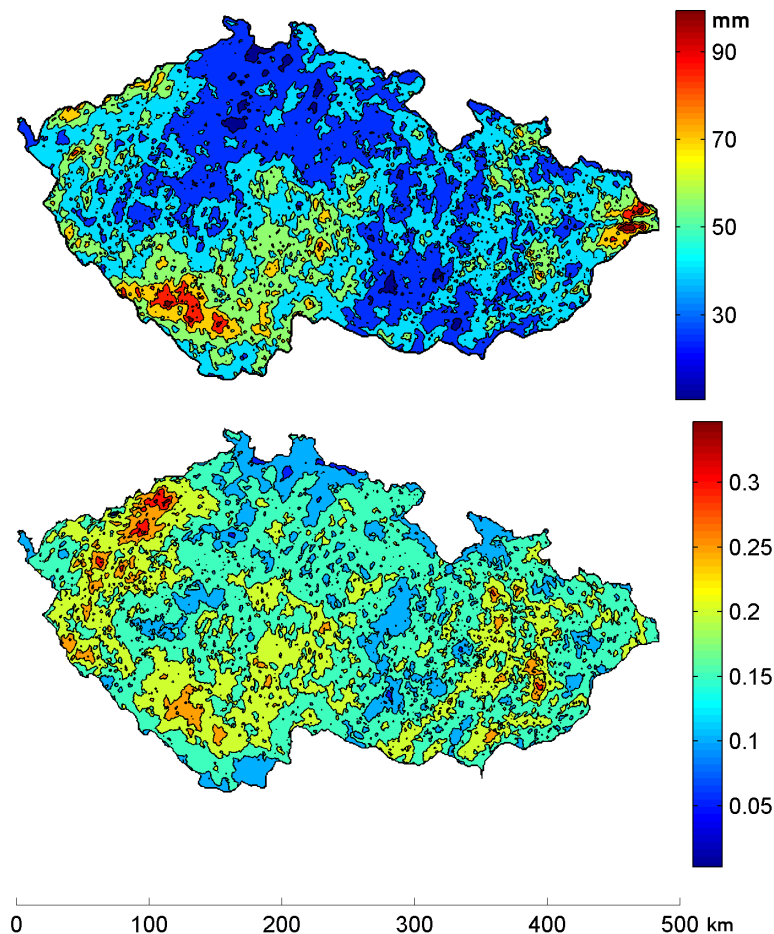

Fig. 3. Heavy rain totals, with $T_{\text {prec }}=5 \mathrm{~mm}$ (up) and ratio of heavy rain totals to annual precipitation amount for warm period of years (down).

Table 1. Correlation coefficients of heavy rain - orography relationships. The bold values are significant on the level $\alpha=0.05$.

\begin{tabular}{lcc}
\hline & altitude & roughness \\
\hline rain totals & & \\
$T_{\text {prec }}=5 \mathrm{~mm}$ & $\boldsymbol{r}=\mathbf{0 . 4 3}$ & $\boldsymbol{r}=\mathbf{0 . 1 8}$ \\
$T_{\text {prec }}=6 \mathrm{~mm}$ & $\mathbf{0 . 1 4}$ & $\mathbf{0 . 1 9}$ \\
$T_{\text {prec }}=7 \mathrm{~mm}$ & $\mathbf{0 . 1 4}$ & $\mathbf{0 . 2 1}$ \\
$T_{\text {prec }}=8 \mathrm{~mm}$ & 0.10 & $\mathbf{0 . 1 6}$ \\
& & \\
rain frequencies & & \\
$T_{\text {prec }}=5 \mathrm{~mm}$ & $\boldsymbol{r = 0 . 5 0}$ & $\boldsymbol{r}=\mathbf{0 . 2 0}$ \\
$T_{\text {prec }}=6 \mathrm{~mm}$ & $\mathbf{0 . 1 8}$ & $\mathbf{0 . 2 5}$ \\
$T_{\text {prec }}=7 \mathrm{~mm}$ & $\mathbf{0 . 1 9}$ & $\mathbf{0 . 2 8}$ \\
$T_{\text {prec }}=8 \mathrm{~mm}$ & 0.11 & $\mathbf{0 . 2 3}$ \\
\hline
\end{tabular}

procedure for heavier rain datasets defined by the thresholds $T_{\text {prec }}=6,7$ and $8 \mathrm{~mm}$. In Table 1 , we summarize resulting correlation coefficients between altitude and rain totals. The correlation coefficients that were significant on the level $\alpha=$ 0.05 are in bold. We observe that the correlation strongly decreases in cases of a threshold value $T_{\text {prec }} \geq 6$, nevertheless it is still significant for $T_{\mathrm{prec}}=6$ and $7 \mathrm{~mm}$. In the case of $T_{\mathrm{prec}}=$ $8 \mathrm{~mm}$ correlation ceases to be significant.
Similarly we examined also the correlation with terrain roughness (see Table 1$)$. For all thresholds $\left(T_{\text {prec }}=5,6,7\right.$ and $8 \mathrm{~mm}$ ), all correlation coefficients are significant, even for the extreme heavy rain totals $\left(T_{\text {prec }}=8 \mathrm{~mm}\right)$. Notice the lower correlation for $T_{\text {prec }}=5 \mathrm{~mm}$ (see Table 1$)$.

\subsection{Heavy rain frequencies and intensities}

In our dataset, the heavy rain totals refer to the product of summing the hourly data. For the correlation to altitude it is not important if the heavy rain total at a locality (in one pixel) was created by more (or longer) rainfalls or more distinct shorter rainfalls. Nevertheless, we can study whether the relation to altitude is caused primarily by the event frequency (i.e., the number of $1 \mathrm{~h}$ events for the whole period) or by the intensity of the events.

In Fig. 4 we show the distribution of both frequency and intensity for heavy rains defined by different threshold values of $T_{\text {prec }}\left(T_{\text {prec }}=5,6,7,8\right)$. It is clear that the event frequency is responsible for the spatial distribution of the totals. Similar results were presented by Daikaru et al. (2004). The map of frequencies for $T_{\mathrm{prec}}=5 \mathrm{~mm}$ resembles the map of heavy rain totals (correlation coefficient $r=0.83$ ), whereas the spatial distribution of average intensity is much different, $r=0.02$. Also the event frequencies correlate better with altitude than the totals, $r=0.5$. The correlation of frequencies with terrain roughness was significant $r=0.2$ (critical value $r_{k}=0.15$ ) but not very high.

Similarly as in the previous chapter, we examined the correlation of frequencies and altitude for different thresholds, $T_{\text {prec }}=6,7$ and $8 \mathrm{~mm}$. We obtained the following correlation coefficients: $r=0.18, r=0.19, r=0.11$ respectively. Similarly as in the correlation of heavy rain totals with altitude, only the first two values were significant. Concerning the correlation with terrain roughness we obtained $r=0.25$, $r=0.28, r=0.23$, respectively and concluded that the correlation was significant for all thresholds (critical values were all around $r_{k}=0.10$; see also Table 1$)$.

Figure 4 also shows spatial distribution of the average rain intensity during the events. The intensity is significantly higher in generally dry south-east regions with low altitude. (The result is similar also for most of the years.) Let us notice that already Trupl (1958) has shown, using ombrographic measurements, that rain rates are usually larger in lowlands than in mountains in the Czech Republic.

Further, we can see a large difference in event frequencies between heavy rains defined with threshold $T_{\text {prec }}=5$ and $6 \mathrm{~mm}$ in the south-west region. Another important feature appears in the cases of $T_{\text {prec }}=7$ and 8 where we observe extreme heavy rains located along north-west and north-east boundaries (see Fig. 5). 

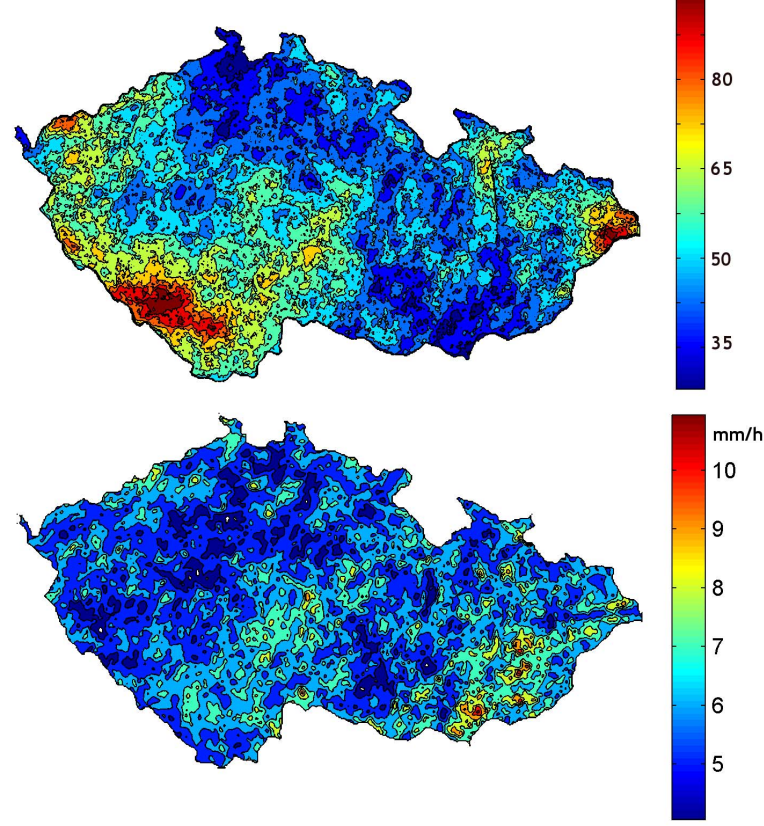

$\begin{array}{llllll}0 & 100 & 200 & 300 & 400 & 500 \mathrm{~km}\end{array}$
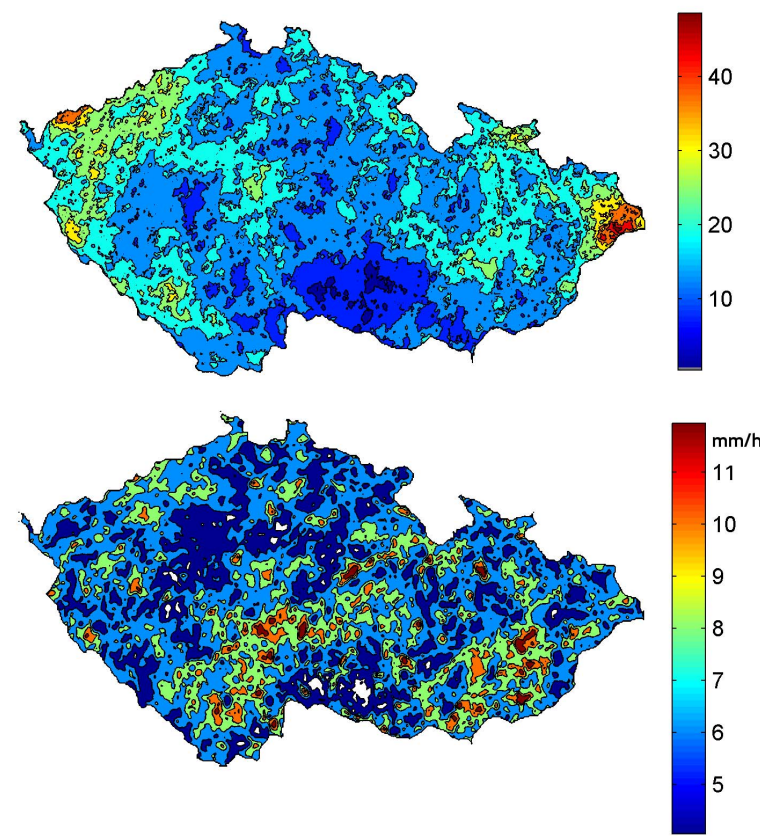

\begin{tabular}{llllll}
\hline 0 & 100 & 200 & 300 & 400 & $500 \mathrm{~km}$
\end{tabular}

Fig. 4. Heavy rain totals split to frequencies (i.e., the number of $1 \mathrm{~h}$ events) (up) and intensities (down), for thresholds $T_{\text {prec }}=5($ left $)$ and $6 \mathrm{~mm}$ (right).

In Fig. 6 we show the altitude distribution of heavy rain frequencies for the cases $T_{\text {prec }}=6,7$ and $8 \mathrm{~mm}$. The density curves for $T_{\text {prec }}=6$ and 7 are relatively close to the density of altitude. Nevertheless we observe that for higher threshold the density of high rains differs more from altitude. The shift of the distribution to higher altitudes is apparent.

\subsection{Correlation within heavy rain events}

Inspired by works studying the precipitation - altitude relationships in mountainous regions (e.g. Haiden and Pistotnik, 2009), we tried to correlate precipitation and altitude within each single event in mountains. The correlation coefficients for all 3568 events are shown in Fig. 7 (up). Despite the fact that the datasets are spatially autocorrelated, we used the standard significance test on the level $\alpha=0.05$. We found that the correlation is significant and positive for $30 \%$ of events and significant and negative for another $30 \%$ of events. Despite such a large proportion of significant correlations, the spatial distribution of these events does not show any regions with prevailing positive or negative correlation (see Fig. 7 - down). We assume that the large proportion is caused by the spatial autocorrelation. These results do not reveal relationships regarding the rain rates and altitude within single events.
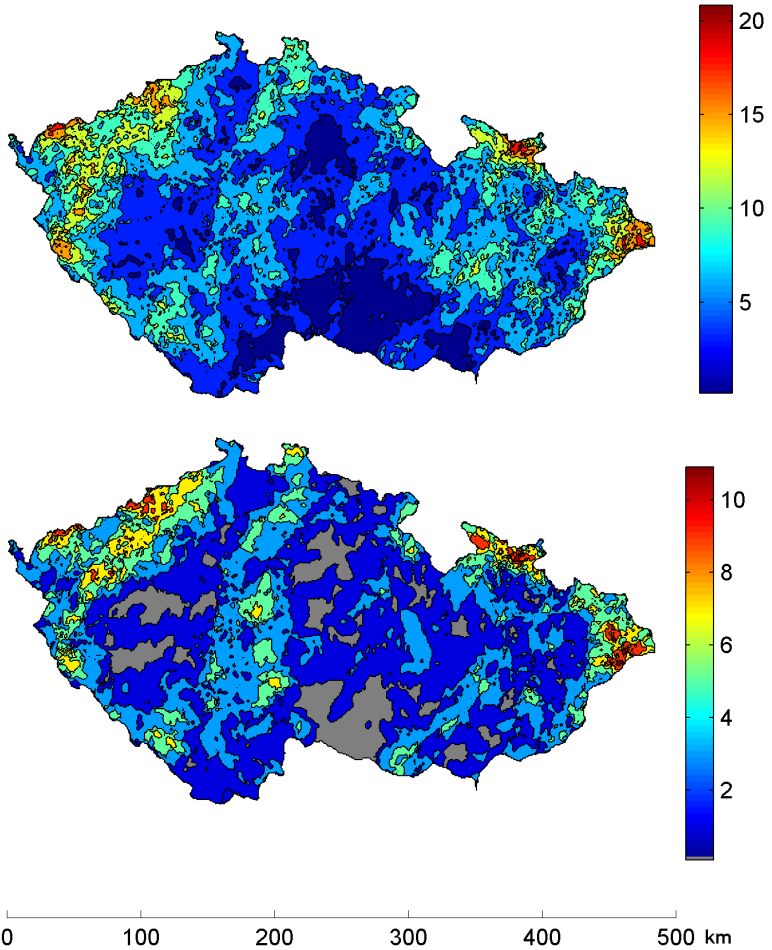

Fig. 5. Heavy rain frequencies for thresholds $T_{\mathrm{prec}}=7$ (up) and $8 \mathrm{~mm}$ (down). 


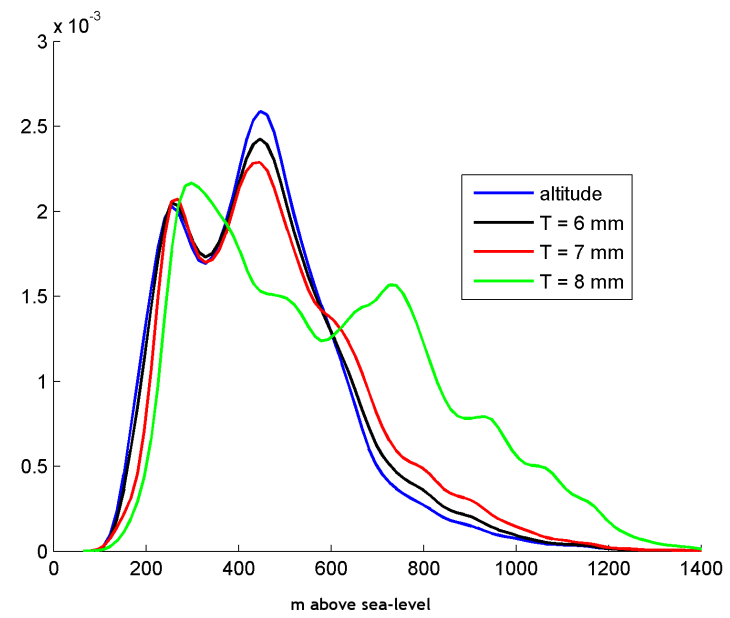

Fig. 6. Altitude distribution of heavy rain frequencies for $T_{\mathrm{prec}}=6$, 7 and $8 \mathrm{~mm}$.

\section{Conclusions}

In this work we studied the dataset of Sokol and Bližňák (2009) using a different method of definition of heavy rain events and examined the heavy rain - altitude and terrain roughness relationships. We organized the data spatially into clusters and used constrains in order to obtain heavy rain events. Then we analyzed spatial distribution of totals, frequencies of occurrence and intensities in relation to altitude and terrain roughness.

We obtained the following results:

1. Heavy rain totals, defined by the threshold $T_{\text {prec }}=5 \mathrm{~mm}$, correlate with altitude globally over the Czech Republic. The correlation decreases with increasing threshold. The correlation with terrain roughness is however significant even for the highest threshold.

2. The correlation of heavy rain intensities with altitude was not proven. The highest intensities are located in the south-eastern parts of the Czech Republic, in relative low altitudes.

3. The spatial distribution of heavy rain frequencies strongly corresponds to the spatial distribution of heavy rain totals. The heavy rain frequencies correlate with altitude even better than the heavy rain totals. The correlation also decreases with increasing threshold. However the correlation with terrain roughness is relatively high and significant even for extreme heavy rain frequencies.

4. The highest percentage of heavy rains in total precipitation is located in the north-western areas.

5. The altitude density curves of heavy rain frequencies indicate a shift of the frequencies to higher altitudes for an increasing rain threshold. The heavier rain set of events the higher altitudes it occupies.
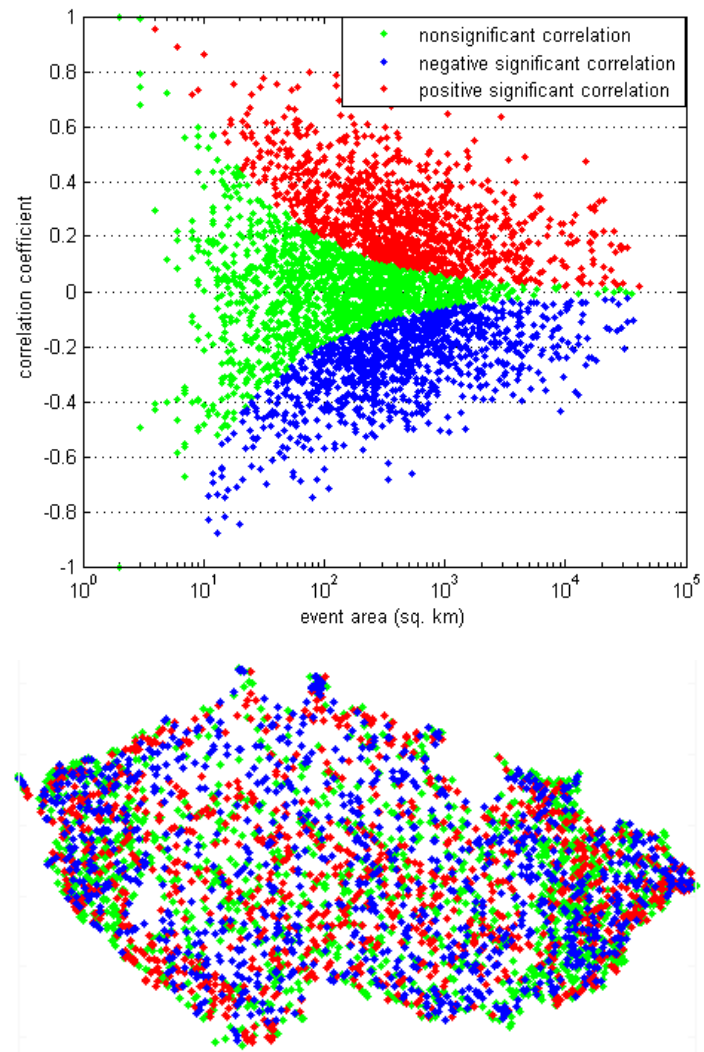

Fig. 7. Correlation between rainfall and altitude data within each single heavy rain event: Up - Dependence of the correlation coefficients on the event area. Down - Spatial distribution of positive significant, negative significant and nonsignificant correlations over the Czech Republic.

6. A correlation of rain rate and altitude within individual events was not found.

7. A generalization of our results is limited due to the relatively short period of observation, which also includes extreme rains that occurred in Central Europe in August 2002.

Acknowledgements. This work was supported by the grant projects GAUK 43-259155, MSM0021620855 and GAUK 43-258018. The original data were kindly provided by the Czech Hydrometeorological Institute.

Edited by: S. C. Michaelides

Reviewed by: two anonymous referees 


\section{References}

Allamano, P., Claps, P., Laio, F., and Thea, C.: A data-based assessment of the dependence of short-duration precipitation on elevation, Phys. Chem. Earth, 34, 635-641, 2009.

Basist, A., Bell, G. D., and Meentemeyer, V.: Statistical relationships between topography and precipitation patterns, J. Climate, 7, 1305-1315, 1994.

Biggerstaff, M. I. and Listemaa, S. A.: An Improved Scheme for Convective/Stratiform Echo Classification Using Radar Reflectivity. J. Appl. Meteorol., 39, 2129-2150, 2000.

Daikaru, K., Emori, S., and Oki, T.: Rainfall Amount, Intensity, Duration, and Frequency Relationships in the Mae Chaem Watershed in Southeast Asia, J. Hydrometeorol., 5, 458-470, 2004.

Davis, A. C. and Hinkley, D. V.: Bootstrap Methods and Their Application, Cammbridge University Press, 1997.

Haiden, T. and Pistotnik, G.: Intensity-dependent parameterization of elevation effects in precipitation analysis, Adv. Geosci., 20, 33-38, 2009,

http://www.adv-geosci.net/20/33/2009/.
Sevruk, B. and Mieglitz, K.: The effect of topography, season and weather situation on daily precipitation gradients in 60 Swiss valleys, Water Sci. Technol., 45, 41-48, 2002.

Sokol, Z.: The use of radar and gauge measurements to estimate areal precipitation for several Czech river basins, Stud. Geophys. Geod. 47, 587-604, 2003.

Sokol, Z. and Bližňák, V.: Areal distribution and precipitationaltitude relationship of heavy short-term precipitation in the Czech Republic in the warm part of the year, Atmos. Res., doi:10.1016/j.atmosres.2009.03.001, in press., 2010.

Steiner, M., Houze, R. A., and Yuter, S. E.: Climatological Characterization of Three-Dimensional Storm Structure from Operational Radar and Rain Gauge Data. J. Appl. Meteorol., 34, 19782007, 1995.

Trupl, J.: Intesity krátkodobých deš v povodích Labe, Odry a Moravy. (Rain rates of short-term rainfalls in catchments Labe, Odra and Morava). Práce a studie, 97, VúV, Prague, in Czech, 1958. 